\title{
Study of the Influence of Initial Conditions on Jacket Structure Launching Operation
}

\author{
Rahmat Jahar, $^{1, a}$, Eko Budi Djatmiko ${ }^{2, b}$, and Yoyok Setyo Hadiwidodo ${ }^{2}$ \\ ${ }^{1}$ Post Graduate Program of Marine Technology, Institut Teknologi Sepuluh Nopember, \\ Surabaya, Indonesia \\ ${ }^{2}$ Department of Ocean Engineering, Institut Teknologi Sepuluh Nopember, \\ Surabaya, Indonesia \\ a.jaharrahmat@gmail.com,b.ebdjatmiko@oe.its.ac.id
}

Keywords: Launching, Trim, Draft, Barge Stability, Bottom Clearance, Rocker Arm Reaction, Jacket Strength.

Abstract: Launching is one of the most hazardous stage in the jacket structure installation. The jacket is launched into the sea by a barge. This study aims to determine the effect of initial launching conditions and analyze the jacket structure during the launching process. The initial conditions of barge trim and draft will be varied to determine the effect of these parameters on barge stability, separation time, rocker arm reaction, jacket bottom clearance, maximum barge trim and jacket strength. Overall 24 variations of initial barge trim and draft have been investigated. The results show that the minimum barge stability range is $49.02^{\circ}$, the minimum area ratio $(\mathrm{K})$ is 12.16 and the minimum metacentric $(\mathrm{GM})$ is $22.90 \mathrm{~m}$. These values meet the limiting criteria of barge stability for launching process. Further, the effect of barge trim is found to be more significant than the draft on the separation time, rocker arm reaction, and maximum barge trim. The effect of barge trim and draft is not significant on the bottom clearance jacket. On jacket strength, there are 14 combinations of barge trim and draft where the structure is safe to be launched as shown by the UC value of less than 1.0.

\section{Introduction}

Characteristics of offshore structures differ from onshore structures. The onshore structure is built and installed on the location where the structure to be operated. While offshore structures should be built in the shipyard then moved, transported and installed at the location of operational site. There are various methods in the process of moving, transporting and installing offshore structures [1]. Installation methods often used are the lifting method, self-floating, and launching. The launching method in the installation of offshore jacket structure has been studied and analyzed as presented in this paper.

The installation by launching method principally is carried out on the jacket structure using launch barge. This method is used if the weight of the jacket structure exceeds the lifting capacity of the available crane. The jacket is transported from the shipyard to the installation site using a barge. When arriving at the location, the barge is ballasted with a certain trim and sea fastening removed so that 
the jacket slides into the sea [2]. In this respect launching process can be divided into 4 stages [3], as follows:

1) Ballasting stage: the barge is ballasted to a certain trim and draft,

2) Sliding stage: the jacket slides on the barge due to its self-weight to the rocker arm,

3) Tipping stage: the jacket slides by tipping the rocker arm then rotating up to the maximum allowable angle and the jacket slides into the sea,

4) Self-righting: the jacket separates from the barge, entering the water surface, then oscillates in a few time span until the jacket afloat in a stable condition.

There are several parameters need to be considered in launching analysis such as trim, draft, $L C G$ $(C o G)$, winch speed, coefficient of friction, drag coefficient, and launch barge specifications [4]. These parameters are specified as initial pre-launch conditions. When the jacket slides along the skidway, the draft and trim that occurs in the launch barge changes and continuously affecting the barge motion responses.

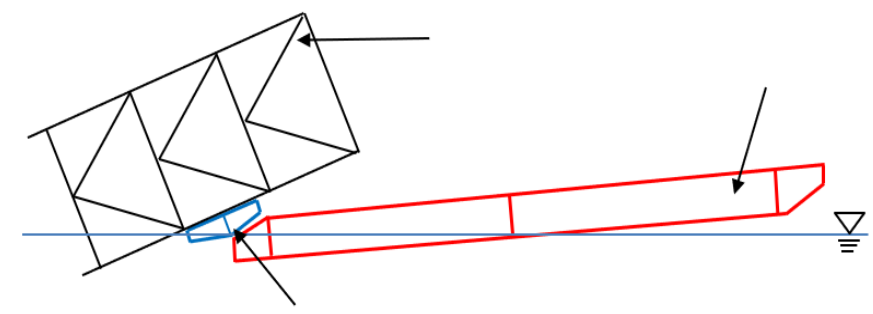

Figure 1: Jacket Slide with Tipping of the Rocker Arm

Other considerations that must be taken during the launching process are the rocker arm reaction, maximum barge trim angle, and jacket's bottom clearance. The rocker arm reaction occurs at the tipping stage as shown in Figure 1, when the jacket slides above the rocker arm and is supported only at one point, namely the rocker arm axis, so that the rocker arm receiving the maximum load [5]. The maximum barge trim angle during the launching should be minimized so as to avoid the risk that may occur onto the barge and on board equipment [6]. Bottom clearance is the minimum gap or distance between the lower part of jacket structure to the seabed at the self-righting stage. Bottom clearance should be considered especially when the jacket height is greater than the water depth, so there is a possibility of jacket impacting onto the seabed. Due to the complexity of the launching process, it is necessary therefore to simulate and study the sensitivity to identify the effect of the launching parameters and initial condition.

Concerning the above, time-history analysis of the jacket launching process is important for several reasons: a) checking that the jacket member can withstand the reaction force generated by the rocker arm, b) the jacket withstand the hydrodynamic forces occurring upon sliding into the sea and, c) ensuring that the jacket will not collide with the seabed [7].

\section{Ship Collision Modelling}

\subsection{Collection Data}

In this study the jacket to be evaluated as a case study is PLCPP2 (Platong Central Processing Platform Number 2) Jacket, configured with 8 legs to be installed using launch barge INTERMAC 650. Detailed information of jacket structure and launch barge is given in the Table 1 and Table 2 . 
Table 1: Number Of Boats On Kenyir Lake

\begin{tabular}{|l|c|c|}
\hline \multicolumn{1}{|c|}{ Items } & Unit & Value \\
\hline Length & $\mathrm{m}$ & 48 \\
\hline Breadth & $\mathrm{m}$ & 48 \\
\hline Depth & $\mathrm{m}$ & 81 \\
\hline Weight & tons & 7285 \\
\hline$V C G(C o G)$ & $\mathrm{m}$ & 34.18 \\
\hline Off centerline $C o G$ abt Row-1 & $\mathrm{m}$ & 0.6 \\
\hline Off centerline CoG abt Row-C & $\mathrm{m}$ & 0.3 \\
\hline
\end{tabular}

Table 2: Number Of Boats On Kenyir Lake

\begin{tabular}{|l|c|c|}
\hline \multicolumn{1}{|c|}{ Items } & Unit & Value \\
\hline Length & $\mathrm{m}$ & 198.12 \\
\hline Breadth & & \\
\hline - forward of midship & $\mathrm{m}$ & 42.06 \\
\hline - aft of midship & $\mathrm{m}$ & 51.82 \\
\hline Depth & $\mathrm{m}$ & 12.19 \\
\hline Light Ship Weight & tons & 19630.7 \\
\hline$L C G$ & $\mathrm{~m}$ & 106.39 \\
\hline$V C G$ & $\mathrm{~m}$ & 8.38 \\
\hline$T C G$ & $\mathrm{~m}$ & 0 \\
\hline
\end{tabular}

\subsection{Sensitivity Analysis}

The purpose of sensitivity analysis is to determine the effect of pre initial launch condition as shown in Table 3. In this study, barge trim and draft will be varied to determine the effect of these parameters on the launching process as shown in Table 4. The analysis results in the launching evaluation are barge stability, rocker arm reaction, bottom clearance jacket, launching duration (separation time), and maximum barge trim angle. Then analyze the jacket structure during the launching process. The launching trajectory consists of three stages:

1) Jacket slides: the jacket slides on the barge due to the pull of the winch or its self-weight without tipping the rocker arm,

2) Jacket tipping: the jacket slides with tipping the rocker arm then rotates and jacket slides into the sea, and

3) Jacket separates: the jacket separates from the barge then oscillates for a certain time until the jacket come to a stable condition.

Table 3: Parameters of Initial Launch Condition

\begin{tabular}{|l|c|c|}
\hline \multicolumn{1}{|c|}{ Parameters } & Unit & Value \\
\hline Water depth & $\mathrm{m}$ & 72.7 \\
\hline Skid height above deck & $\mathrm{m}$ & 1.25 \\
\hline Primary Rocker beam length & $\mathrm{m}$ & 21.31 \\
\hline Secondary Rocker beam length & $\mathrm{m}$ & 10.67 \\
\hline Rocker beam depth & $\mathrm{m}$ & 4.57 \\
\hline Rocker pin from bottom & $\mathrm{m}$ & 7.628 \\
\hline
\end{tabular}




\begin{tabular}{|l|c|c|}
\hline \multicolumn{1}{|c|}{ Parameters } & Unit & Value \\
\hline Rocker pin from bow & $\mathrm{m}$ & 184.405 \\
\hline Jacket from barge bow & $\mathrm{m}$ & 91.2 \\
\hline Friction coefficient $\left(C_{f}\right)$ & - & 0.06 \\
\hline Winch velocity & $\mathrm{m} / \mathrm{s}$ & 0.3 \\
\hline
\end{tabular}

Table 4: Variation of Barge Trim Angle and Draft

\begin{tabular}{|c|c|c|c|}
\hline Trim by Stern $\left(^{\circ}\right)$ & Draft Aft (m) & Draft Midships (m) & Draft Bow (m) \\
\hline \multirow{4}{*}{2.00} & 7.5 & 4.04 & 0.58 \\
\hline & 8.0 & 4.54 & 1.08 \\
\hline & 8.5 & 5.04 & 1.58 \\
\hline & 9.0 & 5.54 & 2.08 \\
\hline \multirow{4}{*}{2.25} & 7.5 & 3.61 & -0.28 \\
\hline & 8.0 & 4.11 & 0.22 \\
\hline & 8.5 & 4.61 & 0.72 \\
\hline & 9.0 & 5.11 & 1.22 \\
\hline \multirow{4}{*}{2.50} & 7.5 & 3.18 & -1.15 \\
\hline & 8.0 & 3.68 & -0.65 \\
\hline & 8.5 & 4.18 & -0.15 \\
\hline & 9.0 & 4.68 & 0.35 \\
\hline \multirow{4}{*}{2.75} & 7.5 & 2.74 & -2.01 \\
\hline & 8.0 & 3.25 & -1.51 \\
\hline & 8.5 & 3.75 & -1.01 \\
\hline & 9.0 & 4.25 & -0.51 \\
\hline \multirow{4}{*}{3.00} & 7.5 & 2.31 & -2.88 \\
\hline & 8.0 & 2.80 & -2.38 \\
\hline & 8.5 & 3.31 & -1.88 \\
\hline & 9.0 & 3.81 & -1.38 \\
\hline \multirow{4}{*}{3.25} & 7.5 & 1.88 & -3.75 \\
\hline & 8.0 & 2.38 & -3.25 \\
\hline & 8.5 & 2.88 & -2.75 \\
\hline & 9.0 & 3.38 & -2.25 \\
\hline
\end{tabular}

\subsection{Sensitivity Analysis}

Modeling the jacket launching process is performed using MOSES 7.10 software, as exhibited in the Figure 2. This is made by combining the jacket structure with launch barge. Coordinate of jacket structure is placed above launch barge. Then launch barge is tilted with a certain trim angle as initial condition of jacket launching process. In modeling, the process of jacket launching begins with defining the skid way with a certain coefficient of friction and rocker arm with a certain turn angle in launching barge. Skid way acts as connector between the jacket structure and launch barge. 


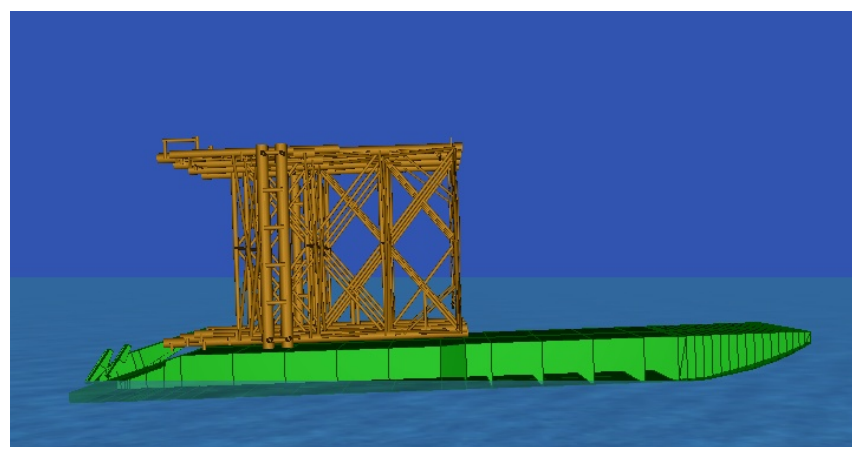

Figure 2: Modeling of the Jacket and Launch Barge by MOSES 7.10

\subsection{Hydrodynamic Forces}

The hydrodynamic force acting on the jacket or barge during launching process, $F h$, can be expressed as the sum of the velocity dependent drag force, $F_{d}$, and the time varying mass and acceleration dependent inertial force, $F a$, as follows [8,9]:

$$
\begin{array}{r}
F h=F d+F a \\
F d=-\frac{1}{2} C d \rho A w \bar{V}_{n}\left|\bar{V}_{n}\right| \\
F a=-M^{\prime} \bar{A}_{n-} \frac{d M^{\prime}}{d t} \bar{V}
\end{array}
$$

where $C_{d}$ is the coefficient of drag, $\rho_{\text {is }}$ the sea water density, $A w$ is the submerged area, $\bar{V}_{n}$ is the normal velocity component, $M^{\prime}$ is the added mass or inertia and $\bar{A}_{n}$ is the normal acceleration. $F_{h}$ may be re-expressed by substituting equations (2) and (3) into equation (1) as:

$$
F d=-\frac{1}{2} \operatorname{Cd\rho Aw} \bar{V}_{n}\left|\bar{V}_{n}\right|-M^{\prime} \bar{A}_{n-} \frac{d M^{\prime}}{d t} \bar{V}
$$

\section{Methodology}

\subsection{Barge Stability}

Before launching process is performed it must be ensured that the launch barge has a sufficient stability. According to the guidelines from Noble Denton international Ltd [4] the criteria of stability for combination between jacket and barge during the launching are:

1) The minimum range of static stability should not be less than $20^{\circ}$,

2) The area under the righting moment curve to the second intercept of the righting moment and wind overturning moment curves or the down flooding angle, whichever is less, shall be not less than $40 \%$ in excess of the area under the wind overturning moment curve to the same limiting angle. Wind velocity used shall be $25 \mathrm{~m} / \mathrm{s}$, or the design wind speed for the towage to location if less, and

3) Metacentric height of the jacket and barge combination shall be positive. 
Results of the stability modeling for combination of jacket and barge during the launching process using MOSES 7.10 are presented in Table V. Data in Table V shows that the minimum range of static stability for all variations of trim angle and draft satisfy the criteria, namely greater than $20^{\circ}$. The minimum ratio area between the righting arm and heel arm is in agreement with the aforementioned second criteria $(K>1.4)$. It is also observed further that launch barge is in stable condition as the value of GM is positive over a variety of trim and draft. Based on the value of GM it can be viewed that the value of stability tends to decrease with increasing of barge draft.

The facts as mentioned above assure all the stability criteria are met over all variation of barge trim angle and draft.

Table 5: Barge Stability Data

\begin{tabular}{|c|c|c|c|c|c|}
\hline $\begin{array}{l}\text { Trim by } \\
\text { Stern }\left(^{\circ}\right)\end{array}$ & $\begin{array}{l}\text { Draft Aft } \\
\text { (m) }\end{array}$ & $\begin{array}{l}\text { Criteria 1 } \\
\left.\text { Range ( }{ }^{\circ}\right)\end{array}$ & $\begin{array}{c}\text { Criteria } 2 \text { Area } \\
\text { Ratio }\end{array}$ & $\begin{array}{c}\text { Criteria } 3 G M \\
\text { (m) }\end{array}$ & Note \\
\hline \multirow{4}{*}{2.00} & 7.5 & 70.26 & 22.25 & 30.59 & Pass \\
\hline & 8.0 & 71.50 & 24.50 & 27.65 & Pass \\
\hline & 8.5 & 72.69 & 26.27 & 25.27 & Pass \\
\hline & 9.0 & 73.89 & 27.72 & 22.90 & Pass \\
\hline \multirow{4}{*}{2.25} & 7.5 & 65.60 & 20.26 & 33.11 & Pass \\
\hline & 8.0 & 69.19 & 22.21 & 29.66 & Pass \\
\hline & 8.5 & 69.99 & 24.30 & 26.98 & Pass \\
\hline & 9.0 & 72.18 & 26.20 & 24.43 & Pass \\
\hline \multirow{4}{*}{2.50} & 7.5 & 60.58 & 18.19 & 35.74 & Pass \\
\hline & 8.0 & 64.93 & 20.05 & 31.97 & Pass \\
\hline & 8.5 & 68.32 & 21.92 & 28.91 & Pass \\
\hline & 9.0 & 70.47 & 23.64 & 26.07 & Pass \\
\hline \multirow{4}{*}{2.75} & 7.5 & 56.15 & 15.87 & 36.30 & Pass \\
\hline & 8.0 & 57.72 & 18.27 & 33.64 & Pass \\
\hline & 8.5 & 64.67 & 19.66 & 30.95 & Pass \\
\hline & 9.0 & 65.96 & 21.83 & 27.85 & Pass \\
\hline \multirow{4}{*}{3.00} & 7.5 & 51.82 & 13.85 & 36.79 & Pass \\
\hline & 8.0 & 55.90 & 15.78 & 33.94 & Pass \\
\hline & 8.5 & 59.01 & 17.79 & 31.87 & Pass \\
\hline & 9.0 & 59.93 & 19.91 & 29.65 & Pass \\
\hline \multirow{4}{*}{3.25} & 7.5 & 49.02 & 12.16 & 37.35 & Pass \\
\hline & 8.0 & 50.35 & 14.11 & 34.28 & Pass \\
\hline & 8.5 & 54.83 & 15.73 & 32.16 & Pass \\
\hline & 9.0 & 57.04 & 17.61 & 30.11 & Pass \\
\hline
\end{tabular}

\subsection{Barge Motion}

The barge and jacket motions such as heave, pitch, and roll at the time of launching for initial condition of trim angle $2.5^{\circ}$ and draft $8.5 \mathrm{~m}$ can be seen in Figure 4-6.

Figure 4 shows the heave motion or the $C o G$ global coordinate change of jacket and barge at $Z$ direction during the launching process. The global coordinate of jacket $C o G$ are $131.89 \mathrm{~m}, 0.36 \mathrm{~m}$, $34.88 \mathrm{~m}(X, Y, Z)$ and the global coordinate of barge $C o G$ are $134.76 \mathrm{~m},-0.08 \mathrm{~m}, 0.38 \mathrm{~m}(X, Y, Z)$. 
The heave motion of jacket decreases over time indicating that the jacket slides and slowly separates from the barge. When the jacket heave motion is at point 0 it means the jacket $C o G$ is parallel to the waterline. While the barge heave motion decreases during the jacket slide and increases when the jacket separates from the barge.

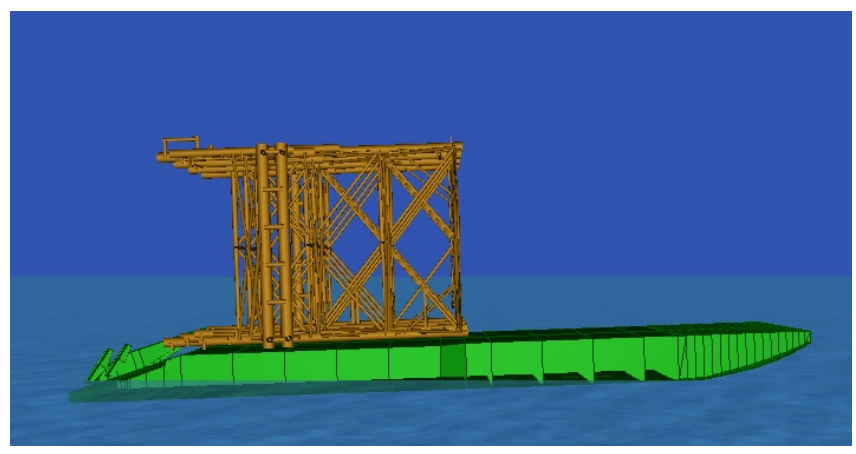

Figure 4: Time History of Jacket and Barge Heave Motions

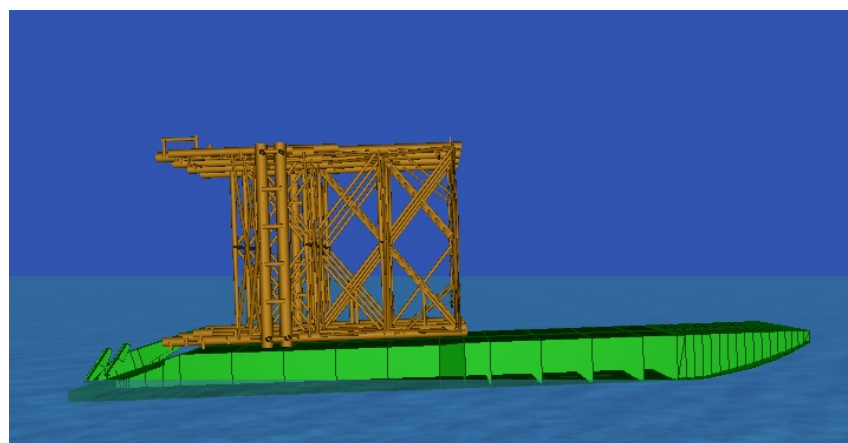

Figure 5: Time History of Jacket and Barge Pitch Motions

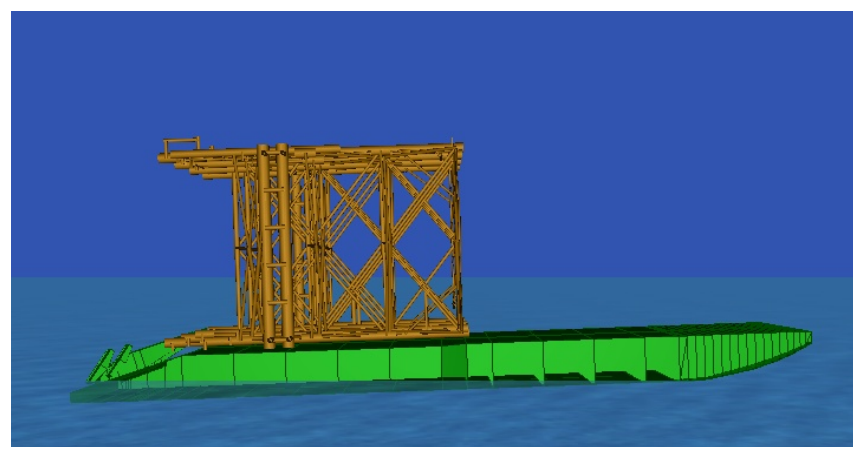

Figure 6: Time History of Jacket and Barge Roll Motions

By observing Figure 5 when the jacket begins to slide toward the rocker arm, the pitch motion change is trivial. The angle between the jacket and the barge begins to increase as the jacket is above the rocker arm. Jacket begins to rotate or termed as jacket tipping, take place at 140.5 secs after sliding from its initial position. The jacket pitch motion gets greater until it reaches its peak of $52.3^{\circ}$ when the jacket begins to detach from the barge or jacket separates and slips into the sea at 148.25 secs.

Barge and jacket roll motions can be seen in Figure 6. The roll angles of jacket and barge begin to increase when the jacket is above the rocker arm and begins to rotate or jacket tipping, precisely at 140.5 secs. Jacket roll angle became greater when the jacket separates from barge at 148.25 secs. The 
barge roll motion barge varies insignificantly, only between $0^{\circ}$ and $0.15^{\circ}$. The jacket roll motion somewhat larger, that is between $-5.63^{\circ}$ and $2.60^{\circ}$.

\subsection{Rocker Arm Reaction}

The maximum reaction of rocker arm occurs when the rocker arm begins to rotate. As shown in Figure 7 rocker arm reaction decreases with the increase in initial barge trim. The main cause is gravity effect on the jacket. When the initial trim angle increases, the jacket component will get a larger force then the frictional force on the jacket decreases and results in larger sliding velocity. The larger the barge trim then the sliding velocity will be greater so the faster the jacket body part immers into water. Jacket body that immers into the water will be supported by the buoyancy so reducing the load of the jacket on the rocker arm.

In Figure 8, particularly at trim $2.00^{\circ}, 2.25^{\circ}$ and $2.50^{\circ}$ show that when the trim angle is small the effect of draft change is not significant to the rocker arm's maximum reaction. Although the rocker arm reaction gets smaller as the trim angle increases, but when the trim angle of the barge is large as in the trim $2.75^{\circ}, 3.0^{\circ}$ and $3.25^{\circ}$, the rocker arm reaction increases with the increase of the initial barge draft. Based on the curves in Figure 8-9, it can be concluded that the trim angle has a greater effect than the draft to reduce the maximum reaction force that occurs in the rocker arm.

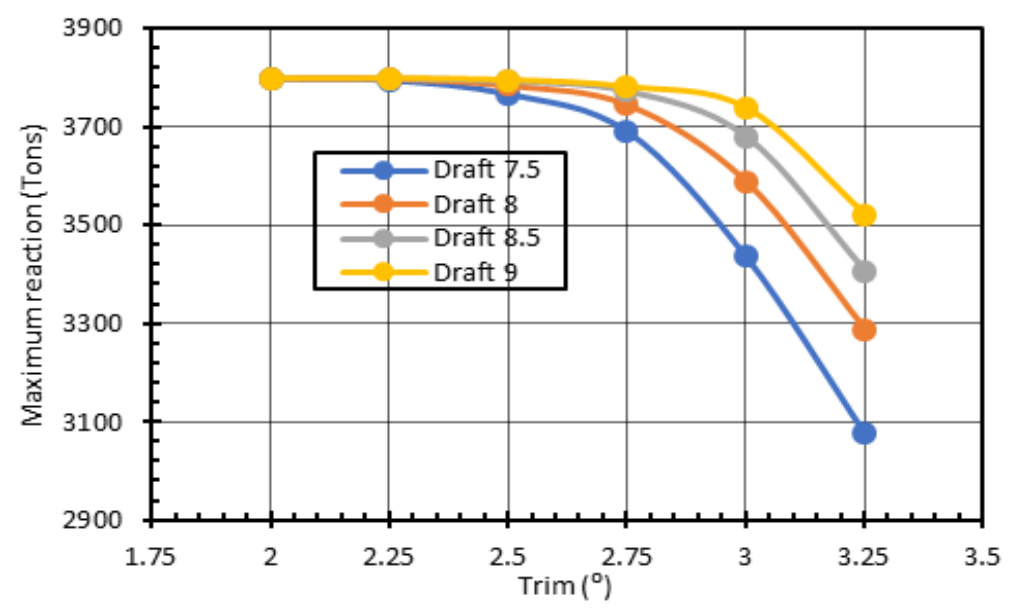

Figure 7: Maximum Reaction of Rocker Arm Versus Barge Trim

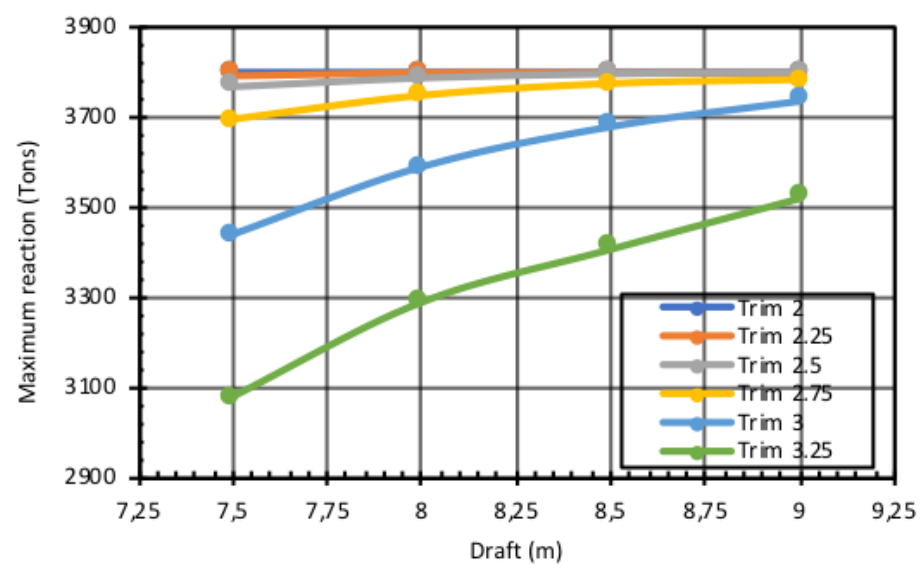

Figure 8: Maximum Reaction of Rocker Arm Versus Barge Draft 


\subsection{Bottom Clearance}

Bottom clearance is minimum distance between the jacket and seabed when jacket slides into the sea. Investigating the bottom clearance is necessary to ensure that jacket will not bump onto the seabed, which can damage the jacket structure.

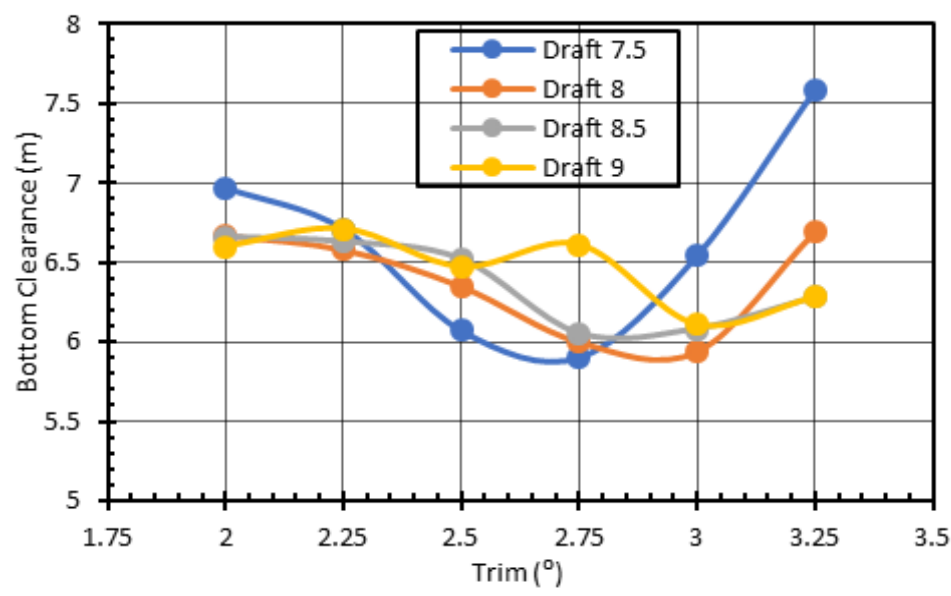

Figure 9: Bottom Clearance Versus Barge Trim

The current modeling gives minimum distance of the jacket to the seabed after launching as can be seen in Figure 9 and Figure 10. The minimum distance is approximately slightly less than $6.0 \mathrm{~m}$ or some $8.25 \%$ of the water depth, which is $72.7 \mathrm{~m}$. This eventually meets the requirements of Nobel Denton International, where the clearance should be greater than $10 \%$ of water depth or not less than $5 \mathrm{~m}$. This fact shows that the jacket launching process is safe to be performed.

The bottom jacket clearance changes with the change of trim and draft. However, the change is not significant, only about $10 \mathrm{~cm}-50 \mathrm{~cm}$ or $0.7 \%$ of the total water depth of $72.7 \mathrm{~m}$. Therefore, any combination of trim and draft will be appropriate to be chosen in term of jacket bottom clearance safety.

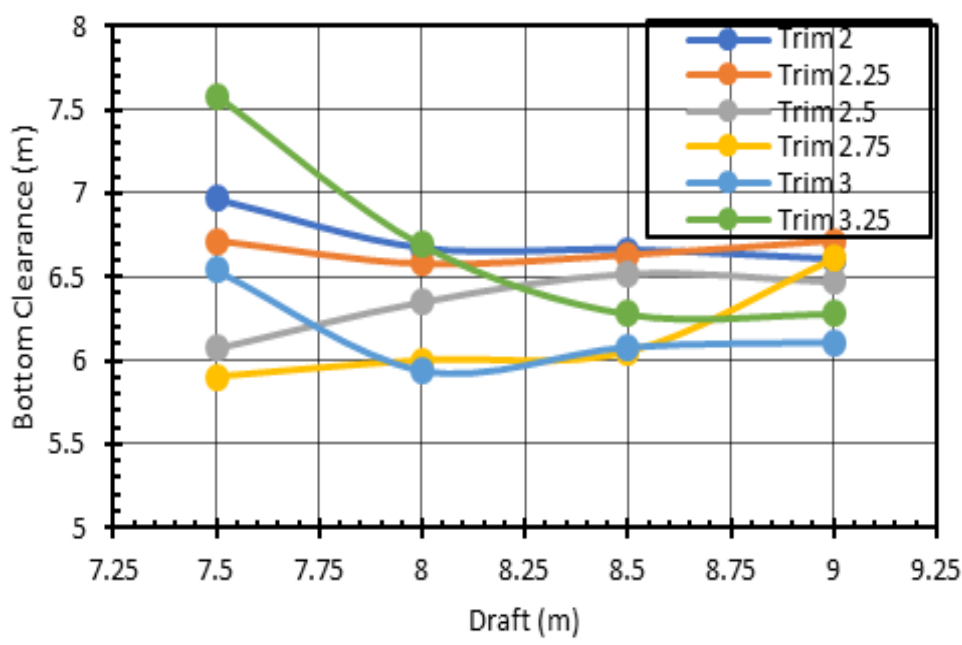

Figure 10: Bottom Clearance Versus Barge Draft 


\subsection{Maximum Barge Trim}

The next aspect that should be investigated during the launching process is the maximum trim angle of the barge. Barge trim angle that is too large during the launching process will cause the risk to the barge and the equipment on it. The effect of trim and draft on the maximum trim angle of the barge can be seen in Figure 11-12. In Figure 11, it is shown the increase in initial trim angle causes the barge maximum trim to become larger. Especially when the draft is small, the maximum barge trim becomes even larger.

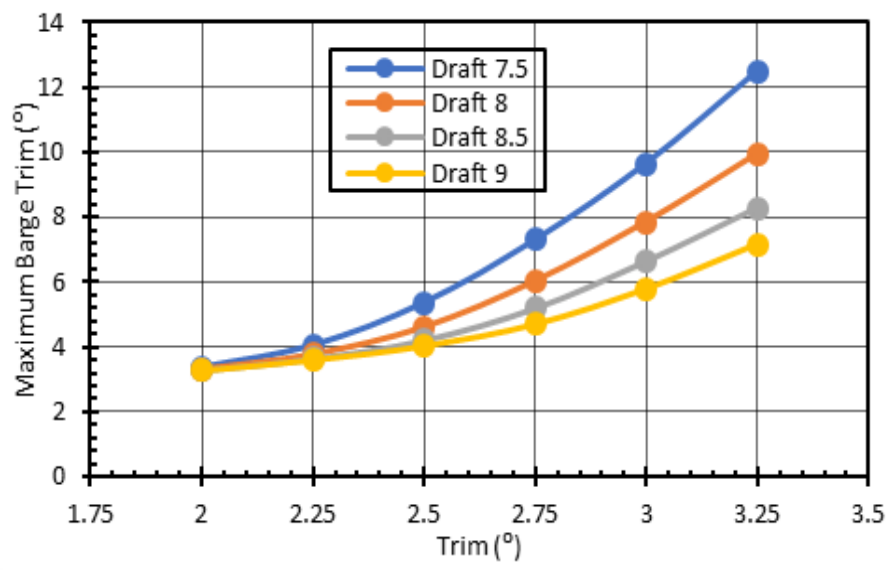

Figure 11: Maximum Barge Trim Versus Initial Barge Trim

Figure 12 presents that when the initial trim angle is small, as in the trim $2.0^{\circ}$ and $2.5^{\circ}$, the change of maximum trim angle is not very significant as the draft increases. However, when the initial trim angle is larger, that is $2.75^{\circ}, 3.0^{\circ}$ and $3.25^{\circ}$ the maximum trim decreases with increasing draft.

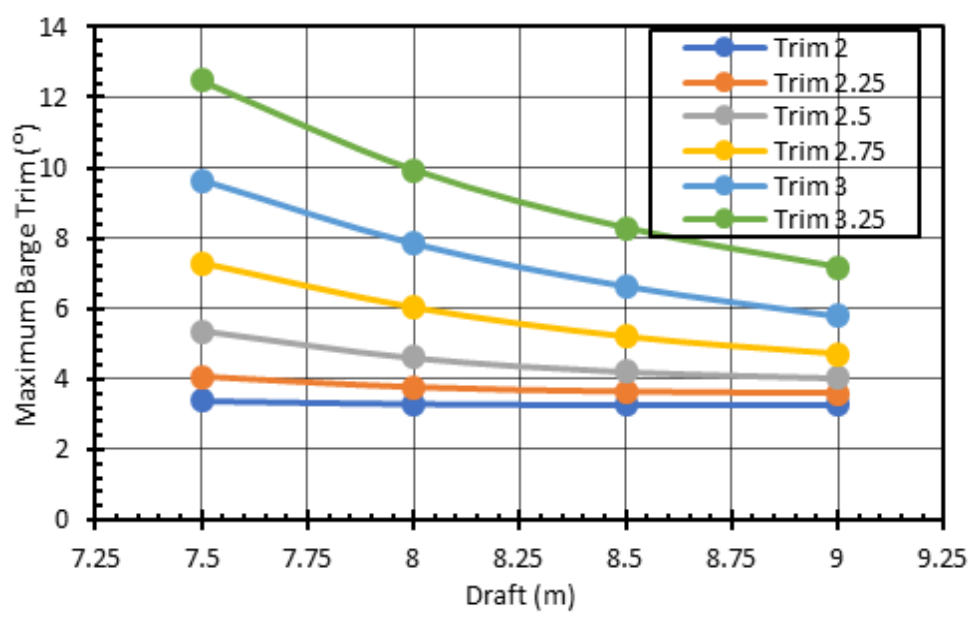

Figure 12: Maximum Barge Trim Versus Initial Draft

\subsection{Jacket Structural Strength}

For the purpose of structural analysis during jacket launching, MOSES 7.10 will create connections modeling of the launch way at each load case. Before tipping, all jacket nodes between the aft end of the tilt beam and the bow of the barge will be restrained. After the tipping, only jacket nodes between the two ends of the tilt beam will be restrained. The selected nodes are then connected 
with compression only springs to the closest barge nodes. For nodes in proper contact with the barge, a nominal stiff spring is used. For those in contact with the tilt beam, this stiff spring is put in series with the bending stiffness of the tilt beam at the proper location $[10,11]$.

Unity check in this research refers to API RP2A standard [12], i.e. allowable stresses for cylindrical members. The API RP2A requires that the stress acting on the jacket should be less than the allowable stresses or UC (unity check) $\leq 1$.

Structural computation to evaluate the jacket strength during launching has been carried out by imposing 24 variations of barge trim and draft determined. The results of structural analysis are listed in Table VI. For each barge trim and draft combination the largest UC of a certain jacket member joint is indicated. It is found here that 14 out of overall 24 variations of barge trim and draft exhibit the structure is safe to be launched, as proven by the UC value which are less than 1.0. The other 10 conditions where present certain members with UC $>1.0$ should not be conducted because it will lead to unsafe operation.

Table 6: Jacket Structural Member Unity Check

\begin{tabular}{|c|c|c|c|}
\hline Trim by Stern $\left(^{\circ}\right)$ & Draft Aft (m) & UC Max & Member \\
\hline \multirow{4}{*}{2.00} & 7.5 & 1.01 & J172C-J176C \\
\hline & 8.0 & 0.84 & J0037-J0096 \\
\hline & 8.5 & 0.83 & J0037-J0096 \\
\hline & 9.0 & 0.84 & J0037-J0097 \\
\hline \multirow{4}{*}{2.25} & 7.5 & 1.02 & J172C-J176C \\
\hline & 8.0 & 0.84 & J0037-J0096 \\
\hline & 8.5 & 0.84 & J0037-J0096 \\
\hline & 9.0 & 0.84 & J0037-J0096 \\
\hline \multirow{4}{*}{2.50} & 7.5 & 0.83 & J167C-J018 \\
\hline & 8.0 & 0.82 & J167C-J018 \\
\hline & 8.5 & 0.84 & J172C-J176C \\
\hline & 9.0 & 0.84 & J0037-J0096 \\
\hline \multirow{4}{*}{2.75} & 7.5 & 0.82 & J0037-J0096 \\
\hline & 8.0 & 0.83 & J172C-J176C \\
\hline & 8.5 & 1.03 & J128B-J129B \\
\hline & 9.0 & 1.00 & J164C-J168C \\
\hline \multirow{4}{*}{3.00} & 7.5 & 1.06 & J128B-J129B \\
\hline & 8.0 & 1.12 & J128B-J129B \\
\hline & 8.5 & 1.14 & J128B-J129B \\
\hline & 9.0 & 0.82 & J0037-J0096 \\
\hline \multirow{4}{*}{3.25} & 7.5 & 1.09 & J128B-J129B \\
\hline & 8.0 & 0.84 & J0037-J0096 \\
\hline & 8.5 & 1.07 & J128B-J129B \\
\hline & 9.0 & 1.08 & J128B-J129B \\
\hline
\end{tabular}

\section{Conclusion}

Result of the jacket launching analysis by considering 24 variations of barge trim angle and draft combination have been described. It is found that the effect of barge trim is more significant than the 
draft on the rocker arm reaction, and maximum barge trim. The effect of barge trim and draft is not significant on the jacket bottom clearance onto the seabed. The minimum barge stability range is $49.02^{\circ}$, the minimum area ratio $(K)$ is 12.16 and the minimum metacentric height $(G M)$ is $22.90 \mathrm{~m}$. Finally, the jacket structural analysis reveals 14 variations of barge trim and draft combination where the structure is safe to be launched as shown by the UC values which are less than 1.0.

\section{Acknowledgement}

Appreciations are conveyed to all parties who have given assistances to the authors in conducting the current study. The first author especially is indebted to LPDP (Indonesia Endowment Fund for Education) for providing the financial support to pursue the post graduate study at ITS.

\section{References}

[1] D.H. Jeong, M.I. Roh, and S.H. Ham, "Lifting simulation of an offshore supply vessel considering various operating conditions," Advances in Mechanical Engineering, vol 8 (6), pp. 1-13, 2016

[2] Soegiono, Teknologi Produksi dan Perawatan Bangunan Laut, Airlangga University Press, Surabaya, 2004

[3] Z. Hu, X. Lin, J. Li, and J.M. Yang, "Comparative study on a jacket launching operation in South China Sea, " Ocean Engineering, vol 111, pp. 335-347, 2016.

[4] Noble Denton International (NDI) Ltd, Guidelines for the Transportation and Installation of Steel Jackets, May. 2002.

[5] C.H. Jo, K.S. Kim, and S.H. Lee, "Parametric study on offshore jacket launching," Ocean Engineering, vol 29, pp.1959-1979, 2002.

[6] X. Lingzhi, L. Xin, Y. Jianmin, and X. Xin, “Study on numerical simulation of jacket launch progress,” Proc. $32^{\text {nd }}$ Int. Conf. on Ocean, Offshore and Arctic Engineering, OMAE 2013, ASME

[7] N. Nourpanah, and M.D. Pirooz, "Numerical modeling of launching offshore jackets from transportation barge and the significance of water entry forces on horizontal jacket members, "Journal of Faculty of Engineering, vol 42, pp. 809-821, 2008

[8] Bentley Systems Inc., SACS User's Manual, 2002

[9] R.W. Prastianto, K. Otsuka, and Y. Ikeda, "Hydrodynamic forces on multiple free-hanging circular cantilevers in uniform flows, " Int. Journ. of Offshore and Polar Engineering, vol. 19, is. 02, June 2009

[10]Bentley Systems Inc, Reference Manual for Moses 7.10, 2014

[11]Murdjito, M.P. Rosari, and E.B. Djatmiko, "Analysis on the critical conditions of side-by-side offloading operation between SSP type-FPSO and shuttle tanker," Applied Mechanics and Materials, vol. 874, pp. 53-63, Jan. 2018

[12]American Petrolium Institute (API), Recommended Practice for Planning, Designing and Constructing Fixed Offshore Platforms-Working Stress Design, API Recommended Practice 2A (API RP2A WSD), Washington, DC, December. 2007 